\title{
LXXVI. A few hints concerning the benefit that may be expected from the nature of coal gas
}

\section{J. W. Davis}

To cite this article: J. W. Davis (1809) LXXVI. A few hints concerning the benefit that may be expected from the nature of coal gas , Philosophical Magazine Series 1, 33:134, 432-438, DOI: $10.1080 / 14786440908562899$

To link to this article: http://dx.doi.org/10.1080/14786440908562899

Published online: 18 May 2009.

Submit your article to this journal $[\pi$

Џll Article views: 2

Q View related articles $\widetilde{ }$ 
For $\frac{a}{b}=\frac{c}{d}$, therefore $\frac{m a}{m b}=\frac{n c}{n d}$, or $m a: m b:: n c: n d ;$ where $m$ or $n$ may be either whole numbers or fractions.

Article XII.-If there be four quantities, such that $a: b:: c: d$, and four others, such that $c: d:: e: f$, then will $a: b:: e: f$.

For, since $\frac{a}{b}=\frac{c}{d}=\frac{e}{f}$, therefore $a: b:: e: f$.

The above articles contain nearly all that is necessary to be understood concerning proportional quantities; and by students 'who know how to manage a simple equation in algebra, they will be read without much difficulty in a very short time. Not being incumbered with equimultiples, the demonstrations are general, and will serve equally for either commensurable or uncommensurable quantities. Very little indeed of what I here send you can be said to be entirely new : it is presumed, however, that the principles on which the above demonstrations are founded, are laid down with more clearness and precision than in any author who has written on this subject. By inserting them in your valuable Miscellany, you will very much oblige your very humble servant,

WM. Marrat.

Boston, May 18, 1809 .

LXXVI. A few Hints concerning the Benefit that may be expected from the Nature of Coal Gas.

\section{To Mr. Tilloch,-Sir,}

$T_{\text {he gas which is obtained when coal is distilled in close }}$ vessels having lately attracted the attention of the public, chiefly on account of its application for the production of artificial light, has encouraged me to lay before your readers a few observations concerning this subject, which bids fair to be ranked among the most beneficial applications of chemical science to the useful purposes of society. I will leave it to your judgement to abridge of these lines, or to cancel, whatever'you deem unworthy of notice, to make room in your journal for more valuable subjects 
you may have received from otber quarters. The brilliancy of the light which is produced during the combustion of coal gas, is so superior in splendour and beauty, that it surpasses not only wax candles and the best spermactio oil, but every other substance hitherto employed for ait ficial illumination. The coke obtained in the same process is so valuable, that it appears inexplicable that men should not avail themselves of this mode of procuring light, to the almost total exclusion of all other methods now in use. As a landholder, placed among an industrious but wholly illiterate society of men, I have had the more opportunity of trying this species of fuel or coke, which I could not otherwise procure in this sequestered spot, at a tolerably cheap rate, for purposes to which it has not, as far as I know, been hithcrto employed. I must tell you that I an my own lime burner, plaster (of Paris) baker, and brickmaker; and that in these processes of rural ceconomy I have derived the greatest benefits from this species of tuel, which I now prepare at a cheap rate, although 1 waste almost the whole of the light of the cual gas intentionally: The coal which I employed formerly for the burning of limestone into lime is a very inferior kind of small coal, called here Welsh culm; the only kind of limestone I can command is the gray kind, which strongly effervesces with acids. It readily splits into distinct layers, and becones perfectly white after having been exposed to a red heat. The kiln for hurning it into lime is a cup-shaped concavily, surrounded with solid brick work, upen at the top, and terminating below by an iron grate. It has a stone door that may be opened and closed tor charging and emprying the furnace when required. This furnace I formerly charged with alternate strata or layers of small coal a dimestone, the latter being broken previously into pieces not lager than a man's fist, until the kiln was completely filled. The stone is thus slowly decomposed; the upper par of the charge descends, and when it has arrived at the bottom of the furuace new strata are super imp ised, so as to keep the furnace continually full during a peried of 50 hours. The quantity of lime I laus procured with small coal formerly Vol.33. No. 134. June 1809. E e amounted 
amounted to 85 bushels. The strata of coal necessary for the production of this quantity of lime require to be four inches thick, and the time absolutely necessary for the process of calcination was, as stated already, 50 hours. On applying coke instead of coal, (which coke I obtained from the same kind of coal,) the produce of lime may be increased to nearly 30 per cent. from the same furnace, and the time required to effect the calcination of this quantity of limestone is reduced to 39 bours : it also requires less attendance and less labour, and the whole saving thus accomplished amounts to more than 50 per cent. on the lime-kiln. I have lately also employed coke for the burning of bricks. My bricks are burnt in clamps made of bricks themselves. The place for the fuel, or fire-place, is perpendicular, about three feet high. The flues are formed by gathering or arching the bricks over, so as to leave a space between each of a brick's breadth; and as the whole of the coal, if this fuel be employed, must, on account of the construction of the pile, be put in at once, the charge of the bricks is not, and never can be, burnt properly thraughout; and the interference of the legislature with regard to the measurement of the clamp is a sufficient inducement for the manufacturer to allow no more place for coal than he can possibly spase:the reason is obvious. If coke be applied instead of coal, the arches or empty spaces in the clamp or pile, as well as the strata of the fuel, may be considerably smaller : the heat produced in this case is more uniform and more intense, and a saving of 32 per cent. at least is gained. In the baking of my own plaster stone (the compact sulphate of lime of a reddish tinge) I also employ coke. The calcination of this stone for manure I perform in a common reverberatory furnace, and the men who conduct the process (who are otherwise averse to every thing new) are much pleased with the steadiness of the fire, and little attendance which the process requires, when coke is used instead of coal. These are the few facts I wish to state to you, with regard to the useful application of this species of fuel, which, no doubt, hereafter will become an object of æconomy of incalculable advantage to individuals, if its nature be better understood 
than it is now. In realing the ingenıus observations of Mr. Accum* with regard to this subject, who states that the effects of different kinds of fuel mas be learnt from the time required to heat a given quantuy of water, \&c., the determining, from the quantity of fuel consumed, the aco. nomical application of different sorts of combustible matters, to ascertain the cost of the one when compared with the cost of the other, particularly arrested my attention win regard to the oconomical application of coke, when compa.ed with fuel of other kinds now in use.

It will not, I am persuaded, be regarded as indicating a wish to detract in the smallest degree from the well-earned credit due to the talents and skill of this chemist, so respectably known to the scientific public, when I venture to state that I am inclined to believe he has rather over-rated the power of coke, in stating it as three to onet, unless his coke be considerably better than mine obtained from Welsh culm. My experiments in the rough way gave about two to one, comparing it with coal weight for weight. I have also no doubt that coke might be advantageously employed in the smelting-houses. 14 pounds of brass can be fused in a portable chemical furnace, by means of coke, in $48 \mathrm{mi}$ nutes, which, with compact wood charcoal, I could not accomplish in less than 1 hour and a quarter. The difference with regard to price in this case is very remarkable. When the coke made from Welsh culm is once complerely ignited, (which it readily is, if not decarburetted too much,) it throws out a very compact and steady heat, and yiejds but a very slight sulphureous odour; and this ceases when it is fully ignited. It lasts a longer time in a state of ignition than charcoal of wood in a quadruple proportion, and its heat is constantly equal, and of almost the same intensity. It also requires less trouble and attendance.

Having stated above, (and as is indeed well known,) that the brilliancy of the light produced during the combustion of coal gas is far superior to oil or candles, and being desirous to know to what this preemirence was owing, I made

* The Report, \&c., page 34. + Ibid. 
a number of experiments, of which I shall merely state the results, and not the proceedings. The gas was prepared from Welsh culm enclosed in a common iron pot covered with a head made of lrick ware; the tubes for conducting the gas were leaden pipes furnished with perforated roses like the extremity of the pipe of a common watering-pot. In this manner it was found that the degree of the illuminating power of the coal gas differs according to the degree of beat employed for its evolution. Cual exposed to a dull red heat, just sufficient for the production of the gas, yielded a gaseous product, which exhibited much less brilliancy when burnt than gas obtained during a temperature of a bright cherry redness.

100 cubic inches of the former gas when made to burn glowly from a small aperture under a gardener's large glass bell, connected with a stone barrel filled with oxygen gas, required 259 cubic inches of oxygen for its complete combustion. On remoying the residual gas into a stone pan containing a ley obtained from the ashes of brush-wood, 114 cubic inches of the gas vanished.

100 cubic inches of coal gas obtained at a cheriy red heat, required for its combustion 312 cubic inches of oxygen gas obtained from oxymuriate of potash. The volume of gas, after having been agitated with a like alkaline ley, lost 117 cubic inches. Hence the light of this gas, or its intensity, is probably in the ratio of the quantity of oxygen necessary for the combustion of the carburetted hydrogen. An increased temperature produces a gas better adapted for illumination than a gas procured by a degree of heat merely sufficient for its evolution.

The gas obtained at a low temperature has a much stronger odour than that produced during an increased temperature. It contains a considerable portion of sulphuretted hydrogen; for on collecting a quantity of it in a gasometer made of two puncheons, the one of which was painted with white lead within, and suffering the gas to stand in this apparatus, it completely blackened the white paint of the wooden vessel. The gas obtained at an increased temperature acted but feebly on the oxide of lead. 
On passing a stream of the gas obtained from Welsh culm through a solution of acetice of lead with excess of acetous acid, it instantly produced a copious black precipitate, which effervesced strongly with nitric acid, and yielded much sulphuretted hydrogen gas.

A quantity of gas which had been repeatedly agitated in contact with a solution of acetite of silver with excess of acid, when suffered to burn under a gardener's bell-glass filled with common air, deposited a dew on the inner surface of the bell; the moisture produced permanently reddened a blue cabbage leaf, and caused a precipitate in acetate of barytes; the precipitate was insoluble in dilute nitric acid; the gas therefore still contained either sulphureous or sulphuric acid; and hence the gas, when intended for the illumination of dwellings, should be procured at a bright red heat. The odour of it becomes under this condition diminished, and the property of blackening paint is but slight and feeble.

The method recommended to deprive the gas of its odotar, by passing it through lime-water, or through lime in a state of ignition, was found to be absolutely insufficient ; continued agitation with lime diffused through water to the consist. ence of cream, with a portion of alkaline ley, was found to deprive the gas of part of its strong odour.

If the gas from coal be suffered to stand over water for some days, or if it be agitated with that fluid, its property of producing a brilliant white light is much impaired. It then burns with a blueish flame instead of a white one: hence, for the purpose of illumination, the gas should be used as it issues from the distillatory vessel.

Whether the sulphuretted hydrogen gas spoken of is an accidental or unavoidable ingredient in the gas of coal, 1 have not been able to learn. Indeed the whole nature of the gas seems to be but ill understood by chemists themselves. For, notwithstanding the merit which Mr. Henry's paper in the Philosophical Transactions for 1808, p. 11, describing an apparatus for the analysis of the compound inflammable gas, contains, the results of his experiments cannot be accurately relied on. The imperfection of the apparatus emE e 3 ployed 
ploved by this philosopher must be obvious to every one; for it cannot separate nor ascertain the nature of above onefifth of the inflammable gas from coal, the composition of the remaining portion being left still undetermined.

The quantity of gas obtained from one chaldron of Welsh culm, I have reason to state, is sufficient to give a quantity of light equal in intensity to that afforded by 869 tallow candles, eight to the pound, burning for 16 hours. The increase of coke in bulk is more than 50 per cent.

The quantity of tar and other condensable products $I$ have not been able to ascertain, owing to the imperfect state of my apparatus. They appear to amount at least to one-tenth of the coal emplnyed. They will probably be found useful hereafter. For cart grease, or to paint palings, \&cc., the tar may certainly be used with advantage.

With the pungent ammoniacal saline liquor $I$ have made no rustic experiment.

J.W. Dayis.

Tanbymoore, May 1, 1809.

LXXVII. On the fertilizing Properties of Manures which contain Ammonia. By Mr. William Cox*.

$I_{\mathbf{T}}$ is only within the last three wecks or a month that any application was made to me for my opinion on the use of any of the articles produced by Mr. Winsor's apparatus, and therefore I have not had the opportunity of making any experiments with this identical ammoniacal liquor, especially with regard to the use to which I beg leave to state I think it applicable. But it will readily be admitted by several gentlemen present, acquainted with chemistry, that ammonia is a chemical matter, as identical in ore situation as in another; and as long as 1 am certain that it is ammonia, it is the same thing if it is produced here or in the North. I was desirous, some years ago, of making ammonia in large quantities, and was of course at some pains

* From Minutes of Evidence taken before the Committee of the House of Commons on the Gas-Light and Coke Company's Bill. 